\title{
Voltage Stability Enhancement by Optimal Placement of UPFC
}

\begin{abstract}
M.Kowsalya*, K.K.Ray*, Udai Shipurkar ** and Saranathan**
Abstract - This paper presents the improvement of the voltage profiles of power system networks by the inclusion of Unified Power Flow Controller (UPFC). The mathematical model of the UPFC is incorporated in the load flow algorithm and the L-index is calculated for the different values of the control parameter $r$ and $\gamma$. The positioning of the UPFC device is changed to minimize the sum of the squares of the L-indices at all load buses. The test cases considered for the improvement of voltage profile with the WSCC 9-bus and IEEE 30 bus system. With the best position of UPFC along with the control parameters the improvement in voltage profile of the power system networks are obtained. The results obtained are quite encouraging compared with other techniques used to identify the best location of UPFC.
\end{abstract}

Keywords: Control parameters, FACTS, L-index, UPFC, Voltage stability

\section{Introduction}

With the increased loading of existing power transmission systems due to increased demand, the problem of voltage stability along with voltage collapse has become a major concern in power system operation, control and planning. With the rapid developments in power electronic devices, FACTS devices have become more attractive for long distance power transmission. Recently, FACTS devices have gained more popularity in power system operations for their contributions in modifying the control parameters to achieve a satisfactory power handling capability [4]-[7]. The Unified Power Flow Controller (UPFC) is one such device considered for regulating the real and reactive power flow independently with adaptive control strategy. Thereby, it offers necessary functional flexibility for the combined application of phase angle and voltage magnitude control through series and shunt compensation. The major advantages of embedding UPFC in power system is not only improves the power handling capability with out changing the transmission network or installing new generations plant but also reduces the generations cost through utilizations of excess power available.

With the application of UPFC, which controls active and reactive component of power, the effect on system voltage stability margin improves and the voltage collapse criteria changes. In order to have an effective utilization of UPFC, proper location of UPFC is a major concern.

This paper aims to locate an ideal placement of UPFC to achieve maximum utilization of the device. To obtain the optimal values of the control vectors $(\mathrm{r}, \gamma)$ for the UPFC, Lindex [1] initially used to place the UPFC in the weakest

\footnotetext{
* Associate Professor \& Senior Professor, School of Electrical Sciences, Power Electronics and Drives Division, VIT University, India. +919791114931(mkowsalya@vit.ac.in, kkray@vit.ac.in )

** Under graduate Scholar, School of Electrical Sciences, VIT University, Vellore, India.
}

Received 2 September 2008; Accepted 10 August 2009 bus. In this paper the author identifies the new index $\sum L^{2}$ to improve the overall stability margin of the system by locating the best position of UPFC for the obtained control parameters $(\mathrm{r}, \gamma)$.

Section 2 gives a defined calculation of stability index; Section 3 gives power model with UPFC along with the analytical equations. Validation of the proposed index is carried out with the WSCC 9-bus system and IEEE 30-bus system.. The results discussed in section 5 .

\section{Calculation of Stability Index}

In order to prevent the occurrence of voltage collapse, it is essential to accurately predict the operating condition of a power system. Kessel et al. developed a voltage stability index based on the solution of the power flow equation [1]. The L-index is a quantitative measure for the estimation of the distance of actual state of the system stability limit. The L- index describes the stability of the complete system. A load flow result is obtained for a given system operating condition which is otherwise available from the output of an on line estimator. The load flow algorithm incorporates load characteristics and generator control characteristics.

For an n-bus power system, buses can be separated into two groups: Bring all load buses to the head and denote them as $\alpha_{\mathrm{L}}$ and put the PV buses the tail and term them as $\alpha_{G}$ i.e., $\alpha_{L}=\left\{1,2, \ldots \ldots, n_{L}\right\} \quad$ and $\alpha_{G}=\left\{n_{L}+1, n_{L}+2, \ldots \ldots . n-1\right.$, $\mathrm{n}$ \}, where $\mathrm{n}_{\mathrm{L}}$ is the number of load buses. The following hybrid system equation is then obtained:

$$
\left[\begin{array}{c}
V^{L} \\
I^{G}
\end{array}\right]=\left[\begin{array}{ll}
Z^{L L} & F^{L G} \\
K^{G L} & Y^{G G}
\end{array}\right]\left[\begin{array}{c}
I^{L} \\
V^{G}
\end{array}\right]
$$

Where $\mathrm{Z}^{\mathrm{LL}}, \mathrm{F}^{\mathrm{LG}}, \mathrm{K}^{\mathrm{GL}}$, and $\mathrm{Y}^{\mathrm{GG}}$ are sub-block of matrix $\mathrm{H} ; \mathrm{V}^{\mathrm{G}}, \mathrm{I}^{\mathrm{G}}, \mathrm{V}^{\mathrm{L}}, \mathrm{I}^{\mathrm{L}}$ are voltage and current vector of PV buses and load buses respectively. Voltage stability index $\mathrm{L}_{\mathrm{j}}$ for any load bus can be defined as given in equation (2) 


$$
L_{j}=\left|1-\sum_{i=1}^{g} F_{j i} \frac{V_{i}}{V_{j}}\right|
$$

Where the L-index varies between 0 (no-load) and 1 (voltage collapse) which says the stability margin of the system.

\section{UPFC Model}

\subsection{UPFC Model}

The Unified power flow controller is the most comprehensive device amongst the FACTS devices [2]-[3] so far developed. It is well known that this unified controller i.e., the combination of static synchronous compensator (STATCOM) and a static series compensator (SSSC) which are normally incorporated in the system to provide concurrent real and reactive power compensation is achieved by injecting a series voltage which in turn reflected in controlling the line impedance and angle or alternatively real and reactive power flow in the line. A block diagram representation of the series shunt compensation is shown in fig (1)

From the model an analytical equation may be derived to obtain the modified bus voltage.

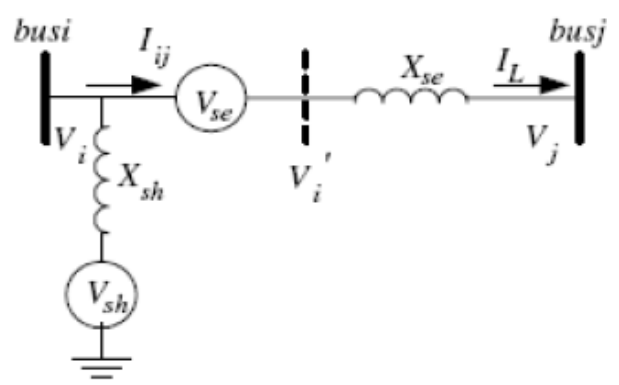

Fig. 1. Equivalent model of UPFC between two buses

Considering the reference voltage for the $i^{\text {th }}$ bus as $\mathrm{V}_{\mathrm{i}} \angle 0$ modified system voltage may be represented by

$$
V_{i}^{\prime}=V_{s e}+V_{i}
$$

The voltage sources $\mathrm{V}_{\text {se }}$ and $\mathrm{V}_{\text {sh }}$ are controllable in both their magnitudes and phase angles through $\mathrm{r}$ and $\gamma$ the control parameters of UPFC whish operates within the following specified limits.

$$
0 \leq \mathrm{r} \leq \mathrm{r}_{\max } \text { and } 0 \leq \gamma \leq 2 \pi
$$

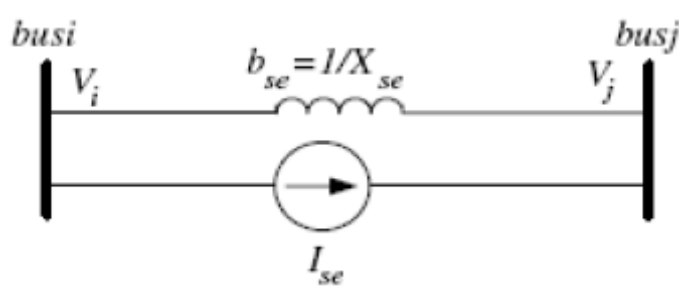

Fig. 2. The Modeling of the series voltage source into an equivalent current source.

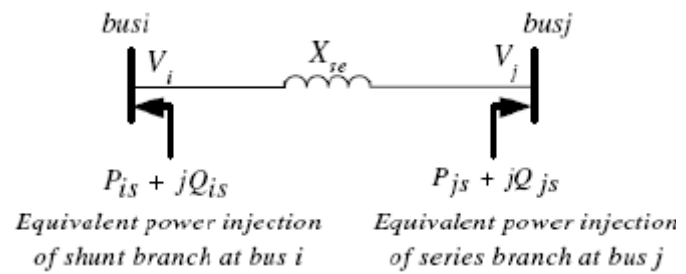

Fig. 3. Power injection model of UPFC in the transmission line

A modified model is developed by replacing the voltage $\mathrm{V}_{\text {se }}$ by a current source $\mathrm{I}_{\mathrm{se}}\left(\mathrm{I}_{\mathrm{se}}=-\mathrm{j} \mathrm{b}_{\mathrm{se}} \mathrm{V}_{\mathrm{se}}\right)$ [8] parallel with the transmission line where $b_{\mathrm{se}}=1 / \mathrm{X}_{\mathrm{se}}$. For simplifying the analysis,

So far the analysis is carried out with UPFC considering the power injected equals to power supplied by the converter in the UPFC. In this paper the analysis has taken into consideration the switching losses of about $2 \%$ of the power transferred i.e.,

$$
P_{\text {SHUNT }}=-1.02 P_{\text {SERIES }}
$$

In this analysis a modified model fig (3) is developed with the above considerations assuming the reactive power $\mathrm{Q}_{\text {SHUNT }}$ is zero. The new mathematical model of UPFC is developed considering the series connected voltage source model with the addition of power injection equivalent to $\mathrm{P}_{\text {SHUNT }}+\mathrm{j} 0$ to bus $\mathrm{i}$.

From the developed model modified jacobian is obtained and the load flow is carried out.

\section{Methodology}

From the load flow solutions of the developed model stated above L-index is obtained to identify the weakest bus which is subsequently loaded to a maximum loading limit. The analysis is carried out by replacing the Unified Power Flow Controller at the identified bus to obtain the Lindex. Similarly, The Load flow solution for L-index is carried out for all the lines. From the results obtained for L-index best locations of the UPFC is found by minimizing the sum of the squares of the L-index for the system as a whole. The proposed technique for the optimal location of UPFC is tested in two cases viz. WSCC 9-bus system and IEEE -30 bus system. The results so obtained are discussed in section 6 .

\section{Implementation}

The developed UPFC model for real and reactive power injections into the system, the load flow studies was carried out with control parameters $r$ varied in steps of 0.1 p.u. and $\gamma$ is varied between 0 to $2 \pi$ for every incremental value of $r$. A graph as shown in fig, is plotted for various values of $r$ and $\gamma$. This analysis is carried out for all possible locations to obtain the best control parameters and the best locations. 


\section{Results and Discussions}

\subsection{WSCC 9-bus system}

The test results for the WSCC 9-bus system having 3 generators is shown in fig. 5.The L-index curve for various loading condition is plotted to identify the weakest bus and its loading limit as shown in fig. 6 .

From the graph it is observed that bus 6 is found to be the weakest bus with a loading limit of 3.879 p.u. With the maximum loading conditions are obtained for bus 6 the UPFC is incorporated and the load flow analysis is performed by varying $\mathrm{r}, \gamma(0 \leq \mathrm{r} \leq 1$ and $0 \leq \gamma \leq 2 \pi)$ and the optimum values are recorded on the basis of maximum stability limit.

A 3-D Plot is drawn with $r$ and $\gamma$ to obtain the stability limit. From the plot, the value of control parameter $r$ is 0.4 and gamma is 2.1 radians the system is more towards stable operating limit of 0.4(fig 6) when the UPFC positioned between the buses 8 and 9 .

The analysis is carried out with UPFC location at different positions to obtain the optimal value of $r$ and $\gamma$ for the calculation for overall stability index i.e., $\Sigma \mathrm{L}^{2}$. The results are tabulated in table 1 .

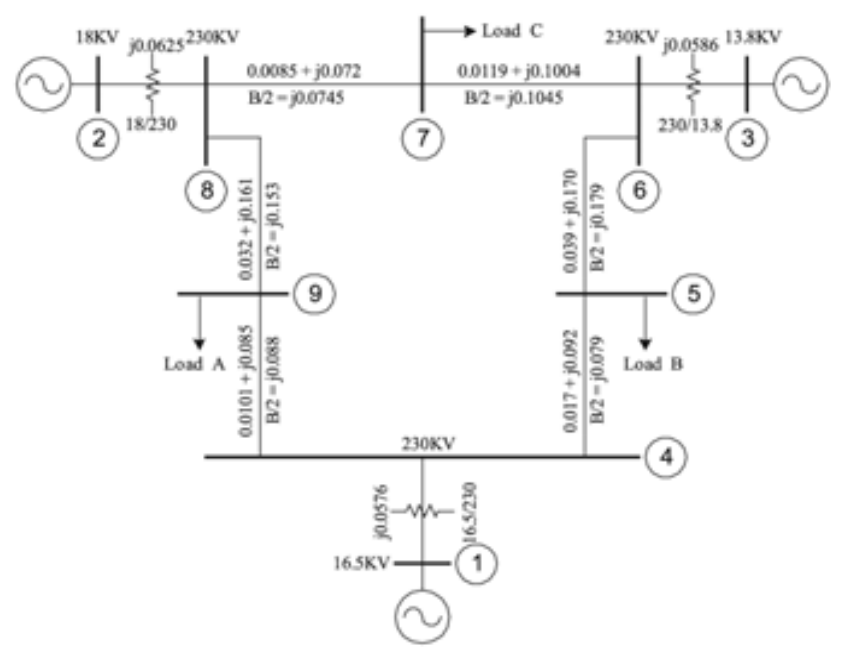

Fig. 4. WSCC 9-bus system

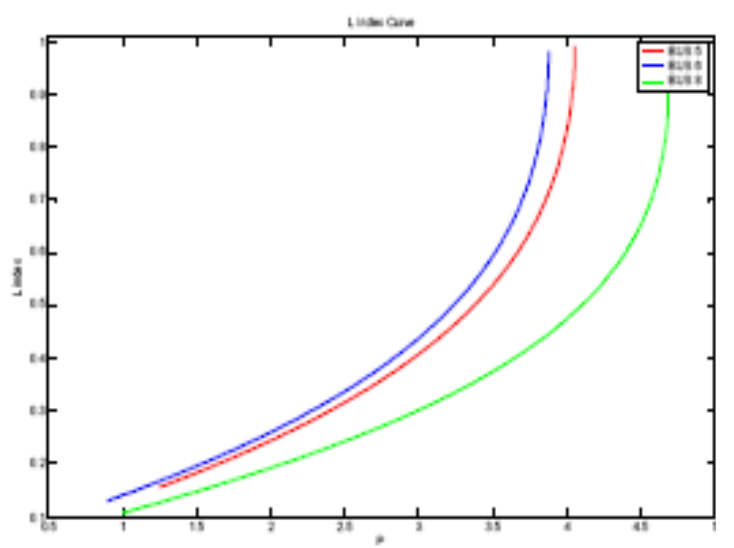

Fig. 5. L-index vs. load bus for each load bus

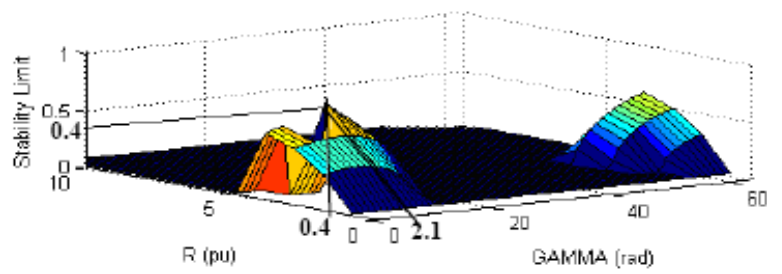

Fig. 6. Stability limit as a function of $r$ and $\gamma$ indicating the stability levels

Table 1. $\Sigma \mathrm{L}^{2}$ for optimum control parameters at each location for the WSCC 9 bus system

\begin{tabular}{|c|c|c|c|c|c|}
\hline CASE & $\begin{array}{c}\text { Fk0M } \\
\text { BUS }\end{array}$ & $\begin{array}{c}\text { T0 } \\
\text { BUS }\end{array}$ & $\begin{array}{c}\mathrm{k} \\
\text { (pu) }\end{array}$ & $\begin{array}{l}\text { GRMMA } \\
\text { (rod) }\end{array}$ & $\overline{\Sigma^{2}}$ \\
\hline 1 & 2 & 7 & 0.4 & 49 & 023691 \\
\hline 2 & 7 & 2 & 09 & 3.7 & 03409 \\
\hline 3 & 3 & 9 & 03 & 03 & 05175 \\
\hline+ & 9 & 3 & 0.7 & 3.6 & 020194 \\
\hline 5 & + & 5 & 03 & 19 & 031979 \\
\hline 6 & 5 & t & ot & 31 & 031891 \\
\hline 7 & 4 & 6 & 03 & 01 & 0.45698 \\
\hline 8 & 6 & 4 & 0.6 & 4.7 & 015676 \\
\hline 9 & 5 & 7 & 0.6 & 3.4 & 05832 \\
\hline 10 & 7 & 5 & 03 & 10 & $0, \$ 5+15$ \\
\hline 11 & 6 & 9 & 05 & d.t. & 016615 \\
\hline 11 & 9 & 6 & 03 & 01 & 014325 \\
\hline 13 & 7 & 8 & $0 t$ & +5 & $0.6720 t$ \\
\hline 14 & 8 & 7 & 03 & 00 & 016312 \\
\hline 15 & 8 & 9 & 0.4 & 21 & 04332 \\
\hline 16 & 9 & 8 & 01 & 61 & 0.87745 \\
\hline
\end{tabular}

From the table it is evident that the lowest value of $\Sigma \mathrm{L}^{2}$ gives the optimum location of the UPFC i.e., between buses 9 and 6 . Bus number 6 through L-index identified as the weakest bus hence the conclusion that the UPFC placement between buses 9 and 6 is the suitable location to obtain the maximum stability limit.

The analysis was carried out for the IEEE - 30 bus system [13]. The results of the analysis were shown in fig 8,9 $\& 10$.

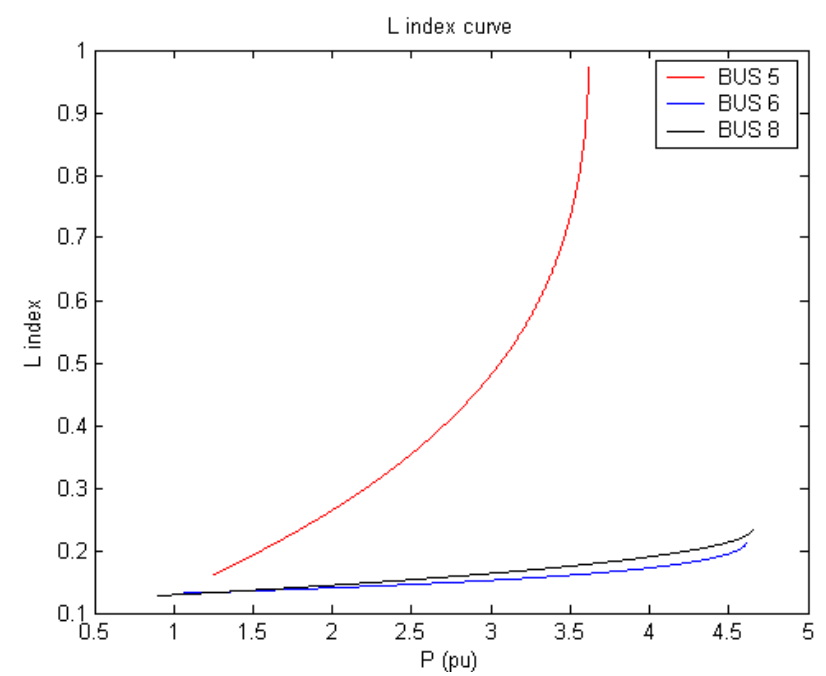

Fig. 7. L-index vs. load bus for the WSCC 9-bus system after inclusion of UPFC in the Optimized position 


\subsection{IEEE 30 bus system}

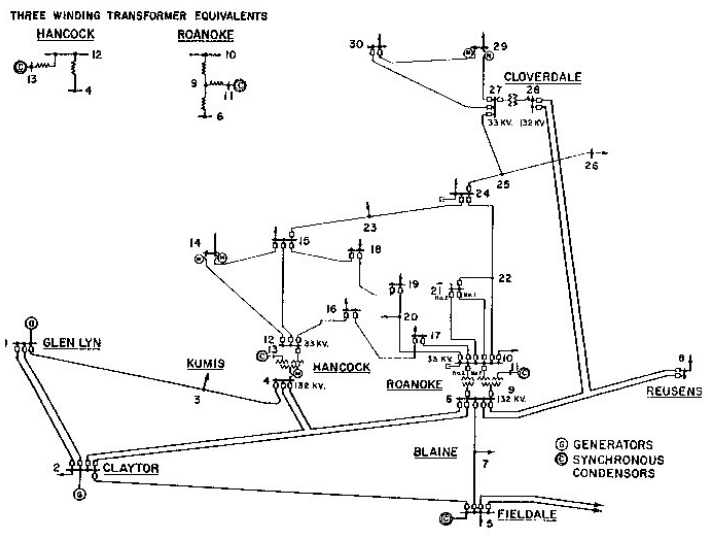

Fig. 8. IEEE 30 bus system

Table 1. $\Sigma \mathrm{L}^{2}$ for optimum control parameters at each location for the WSCC 9 bus system

\begin{tabular}{|c|c|c|c|c|c|}
\hline CANEF & $\begin{array}{c}\text { FRour } \\
\mathrm{ENE}\end{array}$ & TOEVE & $r$ & $Y$ & EI \\
\hline$T$ & 4 & 2 & ó & 42 & $012 \sqrt{2}$ \\
\hline 2 & 2 & 4 & os & 50 & 2 की 5 \\
\hline 3 & 3 & d & 03 & 26 & $112 \%$ \\
\hline 4 & 4 & 3 & os & बा & | 51213 \\
\hline$\xi$ & 2 & $\xi$ & ô & 51 & 0 प्राबड \\
\hline б & $\xi$ & 2 & os & बा & 0 एक्षण0 \\
\hline 7 & 2 & б & 10 & SS & 0 खाos \\
\hline 8 & б. & 2 & os & बा & 01202 \\
\hline 9 & 4 & б & ô & 62 & बडST \\
\hline 10 & 6 & 4 & ô & ô & कारव \\
\hline II & $\xi$ & $?$ & os & 50 & 2ló: \\
\hline 12 & 7 & $\xi$ & 02 & 11 & वहाकरन \\
\hline 13 & б & 7 & 02 & 28 & $235 \%$ \\
\hline 14 & $?$ & б & 02 & S5 & Sस्ञ\$ \\
\hline Is & б. & 8 & ó & 01 & 5 इ \\
\hline 16 & 8 & 6 & od & 31 & S西d \\
\hline 17 & б & 9 & 0 2 & 45 & $1 D S$ \\
\hline 18 & б. & Tó & os & 50 & $2 \mathrm{SIS}$ \\
\hline 18 & 8 & $\pi$ & al & 21 & उष्ष \\
\hline 20 & iI & 9 & al & is & उ S़ा \\
\hline 21 & 9 & Tó & 02 & 5? & $\xi \$ A_{2}^{2}$ \\
\hline 22 & To & 9 & 02 & 53 & 1900 \\
\hline 23 & 4 & 12 & od & 58 & 2\&ाठ́ \\
\hline 24 & 12 & 4 & 02 & 36 & $18 \%$ \\
\hline 25 & 12 & 13 & â & 03 & I $\$ 5.6$ \\
\hline 26 & 14 & 12 & 0 i & dत & इखार \\
\hline 27 & $T_{2}$ & 14 & ai & 03 & हाँ \\
\hline 28 & 12 & Is & ó & 48 & б \\
\hline 20 & IS & 12 & as & बा & बक्पि? \\
\hline 30 & 12 & 16 & 03 & इ1 & SWLE \\
\hline 31 & 16 & 12 & 02 & dú & бớ̛ól \\
\hline 32 & 15 & 14 & 03 & 40 & $6 \%$ \\
\hline 33 & 16 & 17 & al & du & б सBव \\
\hline 34 & 17 & 16 & 02 & 51 & $0 \pi \xi \mid 7$ \\
\hline 35 & 18 & 20 & 02 & 52 & 6120 \\
\hline 36 & 20 & 18 & od & SS & sका \\
\hline 37 & 10 & 17 & ol & 28 & $5 \pi S$ \\
\hline 38 & 10 & 21 & as & हा & 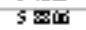 \\
\hline 30 & 21 & 10 & aी & 38 & इख्यक \\
\hline 40 & 10 & 22 & os & 53 & 4 Wod \\
\hline बा & 22 & 10 & ol & 38 & 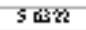 \\
\hline 42 & 21 & 22 & od & 60 & $\sigma 2 \mathrm{Z}^{2}$ \\
\hline 43 & 22 & 21 & os & बा & Glús \\
\hline 44 & is & 23 & 0. 2 & 5? & $12 x$ \\
\hline 45 & 22 & 24 & 01 & 02 & 543 \\
\hline 46 & 23 & 24 & 01 & 58 & ठानक \\
\hline 47 & 24 & 23 & 01 & 58 & 56्रS \\
\hline $4 \Sigma$ & 24 & 25 & 01 & 56 & 5sox \\
\hline 40 & 25 & 24 & ol & d4 & $5 \phi n$ \\
\hline So & 25 & 26 & ol & 58 & 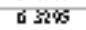 \\
\hline \$ा & 25 & 27 & ol & 44 & sodw \\
\hline \$2 & 27 & 25 & 01 & 56 & 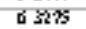 \\
\hline$\$ 3$ & 27 & 28 & 02 & d2 & 1 non \\
\hline$\$ 4$ & 28 & 27 & 02 & 50 & $38 \xi$ \\
\hline S5 & 29 & 27 & 01 & d6 & इ ته\% \\
\hline S6 & 27 & 30 & al & 5S & Elúd \\
\hline \$? & 30 & 27 & oi & d4 & $54 \$ 9$ \\
\hline$\$ 2$ & 20 & 30 & 02 & dE & वरा? \\
\hline 50 & 8 & 28 & 03 & 04 & $18 n$ \\
\hline 60 & 28 & 8 & 03 & 00 & 1.20 \\
\hline हा & б & 22 & ó & का & $111 \%$ \\
\hline 62 & 28 & $\sigma$ & 02 & 31 & 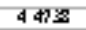 \\
\hline
\end{tabular}

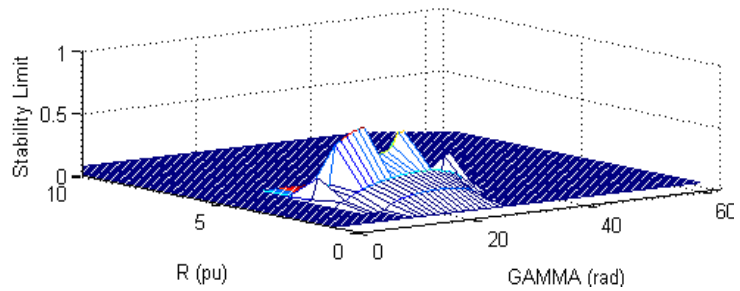

Fig. 9. Stability limit as a function of $r$ and $\gamma$ indicating the stability levels IEEE 30 bus system

From the analysis and results obtained it is clear that the optimum location of UPFC placement to obtain the maximum stability between buses 25-26. Bus number 26 was identified as the weakest bus through L-index with the loading limit of 0.148.p.u.

Fig. 9 shows the 3-D plot between stability index, $r$ and $\gamma$ for the IEEE 30 bus system for the maximum stability limit 0.148 p.u. Again the $r$ and $\gamma$ corresponding to the peak is the optimum values for the given placement.

\section{Conclusions}

From the analysis performed on the test cases, it is evident that UPFC is indeed a device that can improve the stability of a power system and hence allow increase loading.

For the 9-bus WSCC system the optimum placement was found to be between buses 9 and 6 . The control parameters were $\mathrm{r}=0.1 \mathrm{p}$.u. and $\gamma=0.1 \mathrm{rad}$. The instability of the system, represented by $\Sigma \mathrm{L}^{2}$, decreased from 1.2657 without UPFC device to 0.14325 when placed in the position between buses 9-6. The reactive power injected in the UPFC is found to be 0.57964 p.u.

For the IEEE -30 bus system the optimum placement was found to be between buses 4 and 2. The control parameters were $\mathrm{r}=0.6 \mathrm{p}$.u. and $\gamma=4.2 \mathrm{rad}$. The instability of the system, represented by $\Sigma \mathrm{L}^{2}$, decreased from 6.2371 without UPFC device to 0.12392 when placed in the position without UPFC device to 0.14325 when placed in the position between buses 4 and 2 . The reactive power injected in the UPFC is found to be 2.3575 p.u.

It was observed that during the analysis that the placement of the UPFC compensating device at the weakest bus is not necessarily most beneficial to the stability of the system.

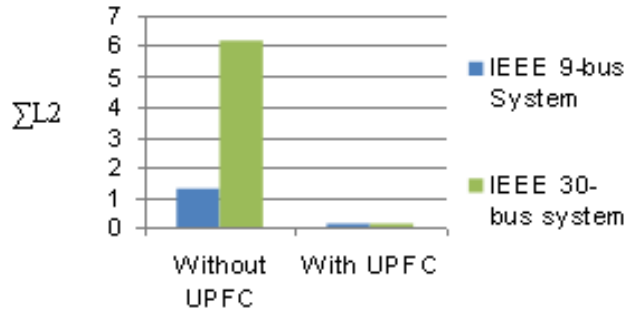

Fig. 10. Reduction in $\Sigma L^{2}$ after insertion of UPFC in the system 
A pictorial representation is the bar graph of fig 10 which shows the reduction in the value of $\Sigma \mathrm{L}^{2}$ depicting an increase in the overall stability

\section{Acknowledgements}

This work was supported by the Vellore Institute of Technology University, Vellore, Tamilnadu, India, 632014.

\section{References}

[1] Kessel P and Glavitsch H., "Estimating the voltage stability of a power system." IEEE Trans. Power Systems, vol. PWRD-1, no.3, pp. 346-352, Feb. 1992.

[2] IEEE Power Engineering Society /CIGRE: 'FACTS Overview' IEEE Service center, Piscataway NJ, 1995, Special issue 95TP108.

[3] IEEE Power Engineering Society: 'FACTS Application' IEEE Service center, Piscataway NJ, 1996, Special issue 95TP116-0.

[4] Narain G. Hingaroni and Laszlo Gyugi, Understanding Facts, Concepts and Technology of Flexible AC Transmission system, IEEE press, 2001.

[5] Y.H.Song, A.Johns, Flexible AC Transmission Systems (FACTS), IEE, London, UK, 1999.

[6] J.Mutale, G.Strbac, Transmssion network and reinforcement versus FACTS: an economic assessment, IEEE Trans Power Systems, Vol 15, no 3, pp. 96-967, 2000.

[7] A.Edris, A.S.Mehraban, M.Rahman, L.Gyugi,S.Arabi T.Reitman, "Controlling the real and reactive power", IEEE Computer Applications on power, January, pp. 20-25,1998.

[8] Mohan Ned. "Power Electronics: Converters, applications, and design" Tata Mc graw hill, 2005.

[9] Kundur P. "Power system stability and control" New York: Mc Graw Hill; 1994

[10] A.MeteVural, Mehmet Tumay, "Mathematical Modelling and analysis of Unified controller: a comparison of two approaches in power flow studies and effect of UPFC location" Electrical power and Energy systems, 29. pp. 617-629, 2007.

[11] K.R.C.Mamundur, et al, "Emergency Adjustments to VAR control Variables to alleviate over voltages, under voltages, and generator VAR limits" IEEE transactions on power systems

[12] http://www.ee.washington.edu/research/pstca/pf30/ ieee30cdf.txt

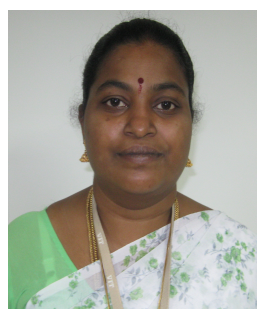

M.Kowsalya She received B.E degr ee in electrical and electronics engi neering and M.E degree in from A nnamalai University, 1995 and 1997. Her research interests are power $\mathrm{s}$ ystem stability, power electronics ap plications in power systems.

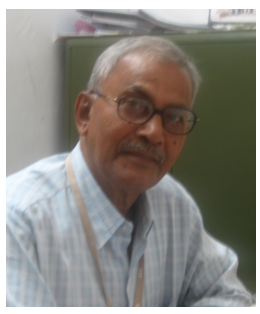

K.K.Ray He obtained his B.E. degr ee in electrical engineering from Ja davpur University, M.Tech degree i $\mathrm{n}$ solid state control from IIT, Kan pur and Ph.D from IIT, Delhi. For mer professor Indian School of Min es, Dhanbad and presently senior pr ofessor, VIT University, India. His area of interests is power electronics, electrical machin es, and reactive power control. 